\title{
A LA BÚSQUEDA DE INSPIRACIÓN. \\ LOS DISEÑOS DE MOBILIARIO DE JOSEP PUIG I CADAFALCH
}

LOOKING FOR INSPIRATION. FURNITURE DESIGNS OF JOSEP PUIG I CADAFALCH

Elisabeth Aisa Suesa*

Investigadora independiente

\section{Resumen}

Josep Puig i Cadafalch, uno de los arquitectos más importantes del modernismo catalán, fue también el diseñador de algunos de los interiores de "sus" edificios. Como en el movimiento Arts \& Crafts británico, quiso que "sus" casas alcanzaran un ideal inspirado en la Edad Media, cuando el trabajo artesanal y la originalidad de los diseños eran primordiales. El contexto catalán, cuya Renaixença había recuperado el medievo como referente, y el franco-belga Art Nouveau fueron claves para su concepción de los edificios como un todo, donde las referencias al estilo gótico estaban muy presentes.

Ahora bien, probablemente por su formación como historiador del arte, otros períodos tuvieron una fuerte influencia en sus diseños de mobiliario. Sus esbozos, conservados en el Arxiu Nacional de Catalunya, nos permiten saber qué otros estilos del pasado le sirvieron de referencia, como el Renacimiento o el Barroco.

Palabras clave: modernismo catalán, estilos históricos, interiorismo, historia del mueble, esbozos.

\section{Abstract}

Josep Puig i Cadafalch, one of the most important architects of the Catalan Modernisme, was also the interior designer of many of "his" buildings. In similar fashion to the British Arts \& Crafts movement, he wanted that "his" houses aimed for an ideal inspired by the medieval past, when the artisan's work and the uniqueness of the resulting interiors were paramount. The Catalan context whose Renaixença had made the Medieval Ages up as a reference and the Franco-Belgian Art Nouveau were key for his idea of the building as a whole, where the references to the Gothic style were usual.

Even that, probably because he was also art historian, other art periods had a very important influence in his furniture designs. His sketches, preserved in the Arxiu Nacional de Catalunya, allow us to see the other past art references that inspired him, as the Renaissance or the Baroque styles.

Keywords: Catalan modernisme, historic styles, interior design, history of furniture, sketches. 


\section{Introducción}

Josep Puig i Cadafalch es uno de los grandes nombres de la arquitectura de finales del siglo XIX y principios del siglo XX. La Casa Amatller, la Casa de les Punxes, el Palau Baró de Quadras fueron residencias que actualmente forman parte del patrimonio modernista de Barcelona. Ahora bien, su legado no se conserva solamente en la Ciudad Condal, pues la Casa Coll i Regàs, en la ciudad donde nació el arquitecto, Mataró, o la Casa Garí, en Argentona, población cercana con la que tuvo grandes vínculos, fueron también diseñadas por él. En ocasiones, los interiores de estos edificios eran proyectos del arquitecto y el material conservado en el Arxiu Nacional de Catalunya (referencia ANC1-737) permite estudiar el mobiliario que diseñó para "sus" casas.

Sin embargo, para reconocer qué le inspiró a la hora de esbozar asientos o escritorios es necesario conocer primero su biografía.

\section{Josep Puig i Cadafalch (1867-1956)}

Nacido en Mataró, en una familia de tradición textil, obtuvo el título de arquitecto en 1891 y ese mismo año abrió su despacho profesional en Barcelona, en la calle Argenteria. En el siguiente, en 1892, sería nombrado arquitecto municipal de Mataró, cargo que ostentó hasta 1896.

Los primeros encargos que realizó en Barcelona fueron la nueva joyería de Josep Macià (su suegro) entre 1893-1894 y la construcción de la Casa Martí, los dos años siguientes. En los últimos años del siglo XIX, Puig i Cadafalch trabajaría a caballo entre la población donde nació y la Ciudad Condal. De hecho, en estos dos municipios se encuentran sus obras arquitectónicas más conocidas: la construcción de la Casa Coll i Regàs en Mataró (1895-1897), la reforma de la Casa Garí en el Cros d'Argentona (1898-1899), la remodelación de la Casa Amatller (1898-1900) y la casa de nueva planta de Romà Macaya (18981900), ambas en Barcelona. Junto con la Casa Serra (1901-1907), la Casa de les Punxes (1903-1905) y el Palau Baró de Quadras (1904-1906), estos inmuebles se enmarcan en el movimiento modernista, en el que las referencias a estilos artísticos del pasado, especialmente del gótico, estaban muy presentes. Sin embargo, que se buscaran influencias en movimientos previos no implica que los copiaran, más bien Puig i Cadafalch los reinterpretó yendo más allá de los “neo-..." (neogótico, neorenacimiento...) que habían estado tan de moda, y les añadió características propias del Art Nouveau que había revolucionado la estética internacional. Como explica Mario Amaya ${ }^{1}$ en referencia a los diseñadores de esa época:

Much Art Nouveau designers returned to these «recherché» periods and places [Japan, Rococo Art, Tudor England, Celtic illuminated manuscripts - the Book of Kells- Tunisia, Persia, Moorish Spain and Turkey], they never actually copied them as their predecessors had imitated accurately the Byzantine, the Renaissance or the Gothic. Instead, they used their models as a jumping-off point for their own invention. 
Años después, a partir de 1910, "sus" edificios empezarían a aproximarse a las ideas del noucentisme, que dejaba atrás la fantasía y las líneas del coup de fouet a la búsqueda de una racionalidad mediterránea y clásica ${ }^{2}$. Ahora bien, lo hizo sin perder ni ciertas referencias históricas, sobre todo barrocas, ni las modas internacionales, ya que la arquitectura germánica y la Sezession tendrían un gran impacto en Puig i Cadafalch. Sería una muestra de esta etapa la Casa Pere Company, en Barcelona, construida en 1911.

En su último periodo como arquitecto, su obra tendió a una monumentalidad más elegante y clásica, reflejada en edificios como la Casa Pich i Pon (1919-1921) o la Casa Casarramona (1921-1923). ${ }^{3}$

Pese a ser ésta probablemente su faceta más conocida, debe tenerse en cuenta que Puig i Cadafalch fue también político (sería regidor del Ayuntamiento de Barcelona entre 1901 y 1906 e incluso acabaría siendo presidente de la Mancomunitat de Catalunya entre 1917 y 1924), periodista (escribiría artículos para el diario La Renaixensa y el semanario La Veu de Catalunya) e historiador del arte (fue reconocido a nivel internacional por sus estudios sobre el arte románico, siendo nombrado doctor honoris causa por cuatro universidades, entre ellas la Sorbona de París en 1930 y la Universidad Autónoma de Barcelona en 1934, dictó un curso y diversas conferencias en Harvard e intervino en diversas excavaciones arqueológicas como el yacimiento de Empúries). ${ }^{4}$ (fig.1)

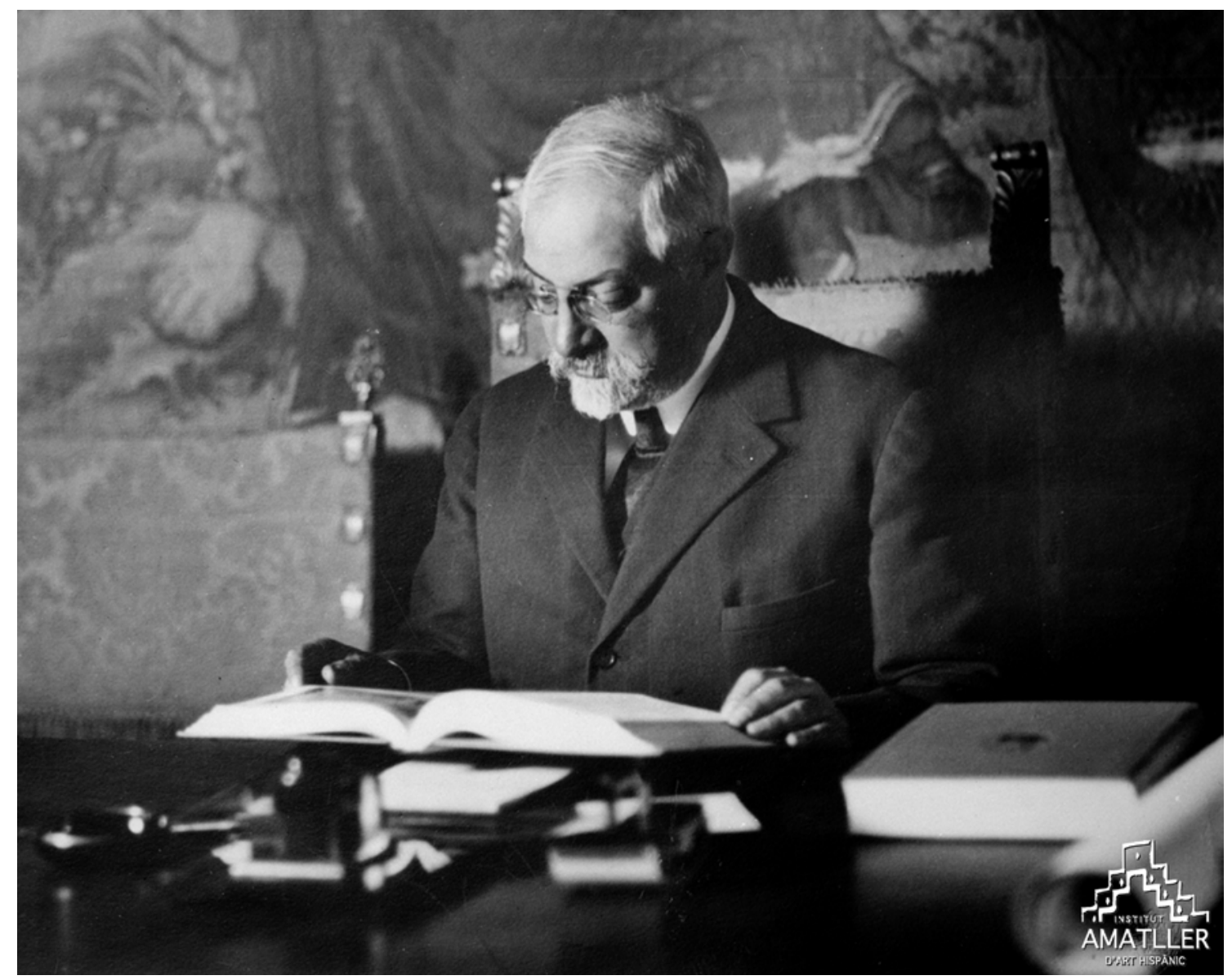

Fig. 1: Retrato de Josep Puig i Cadafalch. 00479011.

Fundació Institut Amatller d'Art Hispànic. 


\section{Josep Puig i Cadafalch como diseñador de interiores}

Al ser una persona tan polifacética, es natural que sus distintos intereses y estudios se vieran influenciados entre ellos, de manera que en sus trabajos como arquitecto, las referencias a estilos arquitectónicos previos son habituales, pero también lo son en sus diseños de interiores.

Él mismo, en su obra L'oeuvre de Puig i Cadafalch architecte 1896-1904, publicada con motivo del VI Congreso Internacional de Arquitectos en Madrid, explica en la introducción la evolución del arte en Catalunya y presenta cuál es la situación de la arquitectura y el diseño en aquel momento: ${ }^{5}$

La tradition artistique de ses écoles gothiques et romanes s'était presque interrompue en Catalogne : l'invasion de la Renaissance, au milieu de sa pauvreté et de sa décadence, était passée par là. Presque la moitié du XIX siècle s'écoula, ne reflétant que pauvrement les styles délicats des écoles françaises. En se réveillant dans une vie nouvelle, exubérante de richesses, la Catalogne voulut se parer aussitôt des splendeurs d'un art qu'il fallait créer, improviser, pour lui permettre d'élever une grande cité.

Et ainsi, à la hâte, s'improvisa l'enseignement architectonique et, plus à la hâte encore, se formèrent les maître et se créèrent les écoles. Dans ce milieu, chacun agissait à sa guise, travaillait à sa fantaisie, soit en cherchant la restauration, d'ailleurs impossible, d'un nouvel art roman, soit en important l'école néo-gothique française de Viollet-le-Duc, soit en songeant à créer un art nouveau puisé en Allemagne, en Autrice et en France ; ou encore en formant un ensemble rationel [sic] d'extériorisation du matériel et de la structure.

Sus diseños serían una amalgama de todas estas influencias y se incluirían otras.

En el Fondo Josep Puig i Cadafalch conservado en el Arxiu Nacional de Catalunya (ANC), que se encontró escondido en la buhardilla de su casa en la calle Provença núm.231 de Barcelona, en una estancia oculta tras una pared falsa de madera ${ }^{6}$, se han podido identificar diferentes dibujos y esbozos, sobre todo de las casas que diseñó en su primera época como arquitecto: la Casa Martí, la Casa Coll i Regàs, la Casa Amatller y la Casa Trinxet, entre otras. A Puig i Cadafalch le gustaba hacer esbozos de sus ideas ${ }^{7}$, ya que, tal y como explican Carla Busquets, Adela Martínez y Rosalba Poveda en su artículo sobre la restauración de algunos de los documentos del Fondo: "els croquis li permetien treballar amb una línia veloç, amb la determinació de saber fins on arribar sense conèixer el camí, línies ràpides com els cotxes dels quals baixava a fer un descans i fer un apunt del paisatge, ràpid". ${ }^{8}$

Muchos de estos esbozos estaban realizados sobre papel de estraza (o papel $k r a f t$ ), fabricado "amb polpa de fusta que ha estat tractada amb agents químics per a disgregar-ne les fibres i per a eliminar-ne aquells elements de la fusta que no són cel lulòsics". ${ }^{9} \mathrm{Al}$ ser un material económico, era habitual utilizarlo para dibujos esquemáticos. ${ }^{10}$ 
Entre estos croquis, se encuentran los materiales a estudiar en este artículo. Esbozos de sillas y arquimesas conviven con los de lámparas y lucernarios. Puig i Cadafalch, además de diseñar edificios, se preocupó de las artes decorativas que iban a verse en ellos.

Este interés por el todo es fruto de su contexto, como se comenta a continuación.

\section{Referentes contextuales}

\section{Nacional}

La trayectoria de Puig i Cadafalch se vio especialmente influenciada, sobre todo en sus inicios, por la Renaixença, "un moviment social i literari que pretenia la recuperació de la identitat catalana"11. Tradicionalmente, se considera su inicio la publicación de la obra Oda a la patria, de Bonaventura Carles Aribau, en 1833, pero su mayor desarrollo se produjo en la segunda mitad del siglo XIX. Fuertemente influenciada por el movimiento romántico europeo y con un gran calado en la burguesía catalana (sobre todo en la barcelonesa) que se había enriquecido a raíz de la revolución industrial, buscó en el pasado cuáles habían sido sus momentos de mayor esplendor en el campo político, histórico, artístico... y encontró en la Edad Media un referente en el que inspirarse. Sería sobre todo en el ámbito cultural donde se reflejarían estas referencias al Medievo: se volvería a escribir en lengua catalana (relegada en los siglos anteriores a raíz de la derrota ante las tropas borbónicas en 1714) y se recuperarían elementos decorativos medievales en la arquitectura y las artes decorativas.

\section{Internacional}

También influyó en Puig i Cadafalch el ideal de John Ruskin y William Morris, desarrollado por el movimiento Arts \& Crafts, que defendía que los objetos además de útiles debían ser bellos. El propio Morris escribiría: ${ }^{12}$

All the furniture and ornament which goes to make up the complete unit of art, a properly ornamented dwelling, is in some degree or other beset with the difficulties which hamper nowadays the satisfactory accomplishment of good and beautiful building. The decorative painter, the mosaicist, the window-artist, the cabinet-maker the potter, the weaver, all these have to fight with the traditional tendency of the epoch in their attempt to produce beauty rather than marketable finery, to put artistic finish on their work rather than trade finish.

Para huir de la mecanización que consideraban que había deshumanizado el trabajo en las fábricas, quisieron recuperar el trabajo artesanal y revalorizar las piezas únicas realizadas a mano. Ya W.A. Pugin, anteriormente, había considerado la Edad Media como el período en que esta labor manual había sido más valorada. Además, estos pensadores concebían los interiores de las casas como un todo, razón por la cual pretendieron huir de la mezcla de estilos que 
había predominado en la época victoriana, buscando unos entornos sencillos e inspirados en la tradición inglesa.

Ahora bien, Judith Rohrer considera que no hay suficientes pruebas documentales como para afirmar que el movimiento británico pudiera influir directa o indirectamente en la arquitectura modernista. ${ }^{13}$ Considera que:

La revifalla dels arts i oficis medievals fou un element essencial de la recerca [...] d'un nou estil nacional basat en la redescoberta del passat en la historia de l'art, i com a tal presentava moltes característiques que distingien aquesta revifalla catalana de fenòmens anàlegs a Anglaterra. La primera és una particular preferència per la restauració d'aquelles tècniques que gaudien d'una particular tradició històrica local; la segona és un entusiasme gairebé exclusiu per desenterrar aquelles tècniques que d'una manera o altra fossin aplicables a l'arquitectura; i la tercera és una profusa aplicació de les tècniques renascudes en un pla decoratiu i quasi emblemàtic a l'exterior dels edificis tant com als interiors. En aquest darrer aspecte, la seva obra s'alinea molt més clarament amb la dels arquitectes belgues i francesos de l'Art Nouveau. ${ }^{14}$

El Art Nouveau, con sus formas organicistas, buscaba conseguir el art total donde el contenedor y el continente formasen un conjunto en el cual ningún detalle decorativo carecía de importancia. Mueblistas, tapiceros,... todos los artistas cuyas obras debían decorar la casa trabajaban juntos para unificar el estilo. La decoración floral, las formas inspiradas en la naturaleza, las figuras femeninas casi etéreas fueron características de este periodo artístico.

\section{Fuentes de inspiración}

Las fuentes que sirvieron de inspiración al arquitecto Puig i Cadafalch fueron muy diversas. Hay algunas que, de hecho, difícilmente se podrán documentar, ya que es probable que elementos cotidianos le sirvieran de referencia: sillas que hubiera en su hogar o mesas que había visto en casa de sus amistades. Por ejemplo, en uno de sus esbozos conservados en el ANC (ANC1-737-N-6 6.103) se puede apreciar un aparador que sigue la estética de los tinells catalanes del siglo XVI, es decir, con una serie de estantes sobre un armario de dos, tres o cuatro puertas en el cuerpo inferior. ${ }^{15}$ Según Lluís Permanyer ${ }^{16}$, este esbozo corresponde a la Casa Martí (futura taberna de Els Quatre Gats, lugar de reunión de artistas como Ramon Casas o Picasso). Por un lado, este aparador era un mueble de ostentación, ya que se podía exponer en los estantes la vajilla de los propietarios y, por el otro, servía de contenedor, gracias al armario de la parte inferior. Se solía ubicar en la parte superior de las escaleras, haciéndoles de techo ${ }^{17} \mathrm{y}$, habitualmente, se encontraba en la sala principal (de hecho en las casas señoriales, la estancia donde se celebraban las recepciones y festividades importantes se conocía como "sala del tinell”). ${ }^{18}$ Ahora bien, también podía estar en el comedor o bien en la cocina. ${ }^{19}$ De estos tinells, había uno en la masia de Can Cabanyes, en Argentona, localidad donde Puig i Cadafalch tenía una serie de propiedades (una heredada, otras dos adquiridas por él) que unificaría en 
una única casa de veraneo. Otro que pudo conocer fue el tinell de Can Bosch que se expone actualmente en el Museu del Disseny de Barcelona y que se ha podido fechar en el año $1574 .{ }^{20}$ La primera persona en documentarlo fue el arquitecto Lluís Bonet Garí, formado al lado de Puig i Cadafalch. De manera que es posible que Puig hubiera visto alguno de estos dos tinells u otro en una de las casas de la zona de donde él era originario.

También los libros fueron fuente de inspiración para el arquitecto. El título de alguno de ellos lo indica el propio Puig i Cadafalch en sus esbozos. Por ejemplo, en el de una cama, se puede leer "Història de l'art de [palabra ilegible] Pag[sic].106" (ANC1-737-T-48). En otro (ANC1-737-N-243), está escrito "Diccionari del moble de Viollet-le-Duc" y, precisamente gracias a esa anotación, el historiador del arte Santiago Alcolea ${ }^{21}$ ya había defendido la obra del francés, concretamente el Dictionnaire raisonné $d u$ mobilier français de l'époque carlovingienne à la Renaissance (1858-1873) como una de las fuentes de referencia del arquitecto catalán. En la Casa Garí, se conserva un sitial muy parecido al de la obra de Viollet-le-Duc, copiado por Puig i Cadafalch, del que tan solo difiere en ciertos detalles. Por ejemplo, en el respaldo, el francés destacó la talla de escudos mientras que Puig resaltó las de coronas, en cambio, los elementos parecidos son más numerosos, como la decoración en pergamino de la parte inferior o el coronamiento del respaldo con pequeños pináculos. (fig.2)

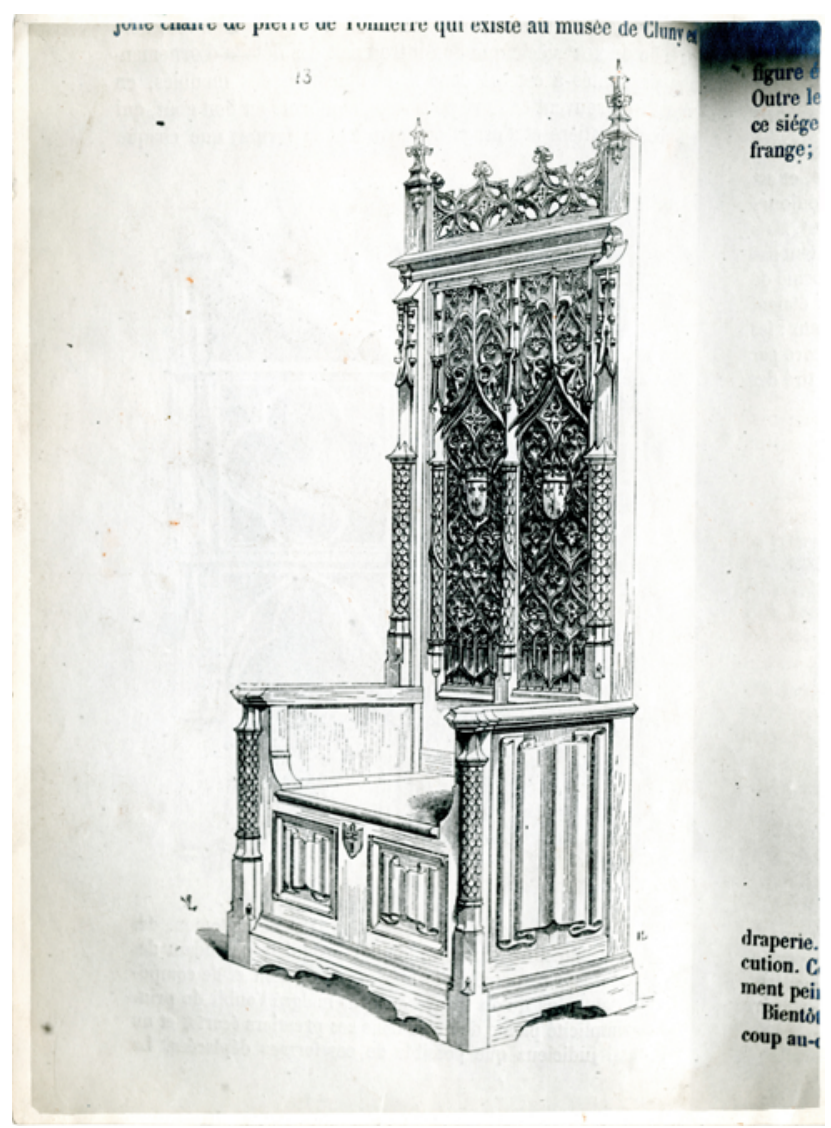

Fig. 2: Dibujo de un trono real de estilo gótico. Dictionnaire raisonné du mobilier français... de Viollet-le-Duc. Imagen 572900. Arxiu Nacional de Catalunya. 
También del Dictionnaire ${ }^{22}$ copiaría la imagen de una Virgen María con el niño Jesús en sus brazos (ANC1-737-N-10 10.113a) que no parece que se llegara a realizar.

Otra obra que le sirvió de referencia, pese a que no dejó ninguna anotación al respecto, fue la Historia general del arte (1886-1901) de la Editorial Montaner y Simón. Es lógico pensar en ella por cronología, pero también porque el propio Puig i Cadafalch participó en la publicación de esta obra junto con el arquitecto Lluís Domènech i Montaner (que era el editor), concretamente en los tres primeros volúmenes centrados en arquitectura. El que trataba sobre el tema del mobiliario era el número ocho que fue escrito por el escritor, coleccionista de arte y periodista Francesc Miquel i Badia. Hojeando sus páginas, se pueden encontrar camas, mesas, armarios,... Entre todos estos muebles, hay la fotografía de un sitial del siglo XV. Dicho sitial se describe como un "sillón de aparato en madera tallada" ${ }^{23}$ y Josep Mainar proporciona más información sobre él al indicar que era "una cadira prioral de la qual George Sand va fer una descripció literària en la seva obra Un hiver à Majorque". ${ }^{24}$ La escritora francesa (George Sand era el seudónimo de Amantine Dupin) conoció este asiento durante su estancia en Mallorca, donde pudo verlo en la Cartuja de Valldemossa. En uno de los esbozos de Puig i Cadafalch (ANC1-737-N-10 10.104a) para la Casa Amatller se puede ver un sitial prácticamente idéntico al recogido por Miquel i Badia y, de hecho, en el Museu del Modernisme se conserva actualmente un mueble como el dibujado por Puig i Cadafalch, realizado a finales del siglo XIX - principios del siglo XX. Es decir, que de esta pieza podría seguirse el recorrido desde el modelo original hasta el mueble final, pasando por el esbozo de Puig, faltando sólo averiguar quién fue el ebanista que lo realizó. ${ }^{25}$ (fig.3)

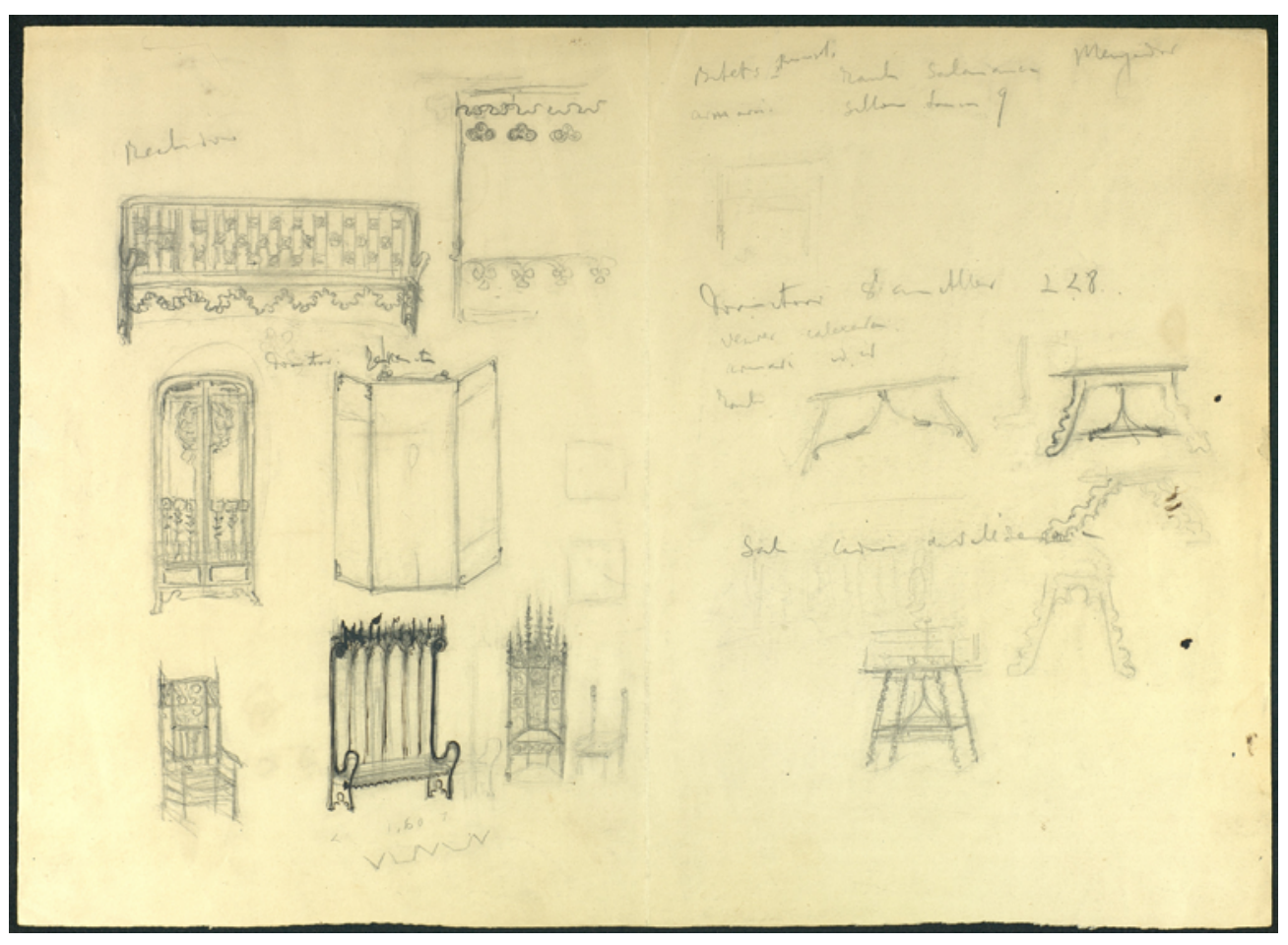

Fig. 3: Esbozos de mobiliario realizados por Josep Puig i Cadafalch para la Casa Amatller. Barcelona. Imagen 901094. Arxiu Nacional de Catalunya. 
De otras fuentes que tuvo, hay algunas pistas. Por ejemplo, se conserva una carta en el ANC (ANC1-737-T-48) del mueblista Miguel Campuzano en la que le notifica el envío de "un folleto con fotografía de algunos de los muebles de mi especialidad, los cuales me permito recomendarle tanto por su construcción, como por su depurado Estilo [sic]". Por tanto, es probable que Puig i Cadafalch se inspirara en mobiliario del que conocía sus diseños por catálogos o recopilaciones de mueblistas y ebanistas de la época.

\section{Estilos que le inspiraron}

Pese a que no se puedan averiguar todas las fuentes bibliográficas o materiales que le inspiraron, al haberse conservado esbozos y muebles diseñados por Puig i Cadafalch, sí que se puede analizar qué estilos artísticos sirvieron de referencia al arquitecto a la hora de realizarlos.

\section{$\underline{\text { Gótico }}$}

Uno de los primeros ejemplos a citar sería el sitial que ya se ha comentado anteriormente, el descrito por George Sand. Para Mainar, este tipo de silla prioral tenía "una caracterologia arquitectònica anàloga a l'obra d'argenteria, quan no la imitaven francament florejant abundosament els pinacles". ${ }^{26}$

Hay otro sitial, en la Casa Garí de Argentona, cuya forma y decoración parecen inspiradas en el conocido como "trono del rey Martí". Éste es descrito por Mainar como "una cadira d'argent daurat [...] que té la particularitat del respatller en tres frontons" ${ }^{27}$. El conservado en la casa Garí no es un mueble metálico, sino que está trabajado en roble. Al no conservarse el esbozo, no se puede trazar la línea completa, pero la decoración en espiral del reposabrazos, la decoración trilobulada de los arcos de la parte inferior... son elementos muy parecidos entre el trono del rey Martí y el sitial de la Casa Garí, de manera que uno podría haber sido inspiración para el otro. Este asiento medieval, concretamente de finales del siglo XIV, también estaba referenciado en el volumen de Miquel i Badia de la Historia General del Arte. ${ }^{28}$ (fig.4)

Esta idea de silla prioral también quedaría reflejada en el trono (ANC1737-N-240) que Puig i Cadafalch diseñó para la reina dels Jocs Florals de Barcelona, certamen poético instituido en la ciudad en 1859. Este mueble se realizó en el año 1908 en ocasión del cincuentenario de la restitución de este certamen cuyo origen data en el reinado de Joan I en el siglo XIV. ${ }^{29}$

Otra tipología de mueble medieval presente en los esbozos de Puig y que se puede ver en las fotografías de época es el escaño, es decir, "un banco con respaldo y brazos macizos" 30 , cuyo momento de máximo esplendor había sido entre los siglos XV y XVI. Se han conservado diversos escaños neogóticos, como el que decoraba la entrada del piso principal de la Casa Lleó i Morera en Barcelona (del que se desconoce el diseñador y el ebanista) ${ }^{31}$ o el realizado en nogal por Francesc Vidal i Jevellí, conservados ambos en el Museu del Disseny de Barcelona. Asimismo, en el movimiento Arts \& Crafts inglés hubo ejemplos de escaños, como el que Philip Speakman Webb diseñó para la sala de estar de la Red House, la vivienda de William Morris. Puig i Cadafalch esbozó escaños 
para diversos edificios y actualmente se pueden encontrar en la Casa Garí y a lado y lado de la chimenea del comedor de la Casa Amatller. ${ }^{32}$ (fig.5)

Viollet-le-Duc también dibujó esta tipología de mueble en sus interiores y uno de sus modelos ${ }^{33}$ fue copiado por Puig i Cadafalch (ANC1-737-N-250 250.119a). Su esbozo, como el del dibujo del francés, tiene una decoración trilobulada en la parte superior y dos arcos decorando el lateral del asiento, en la parte inferior del mueble.

En algunos de estos escaños, incorporó un mueble contenedor bajo el asiento, recuperando así también la característica multifuncionalidad de muchas de las tipologías de mueble medievales, como el arquibanco. Esta característica era muy apreciada entonces, dada la movilidad habitual, sobre todo entre las personas de clases altas. El Modernismo la recuperaría para enriquecer sus muebles, de ahí la existencia en la época de mobiliario como "paragüero-colgador" o "espejo-jardinera", de los que se exhiben varios ejemplos en el Museu del Modernisme. ${ }^{34}$

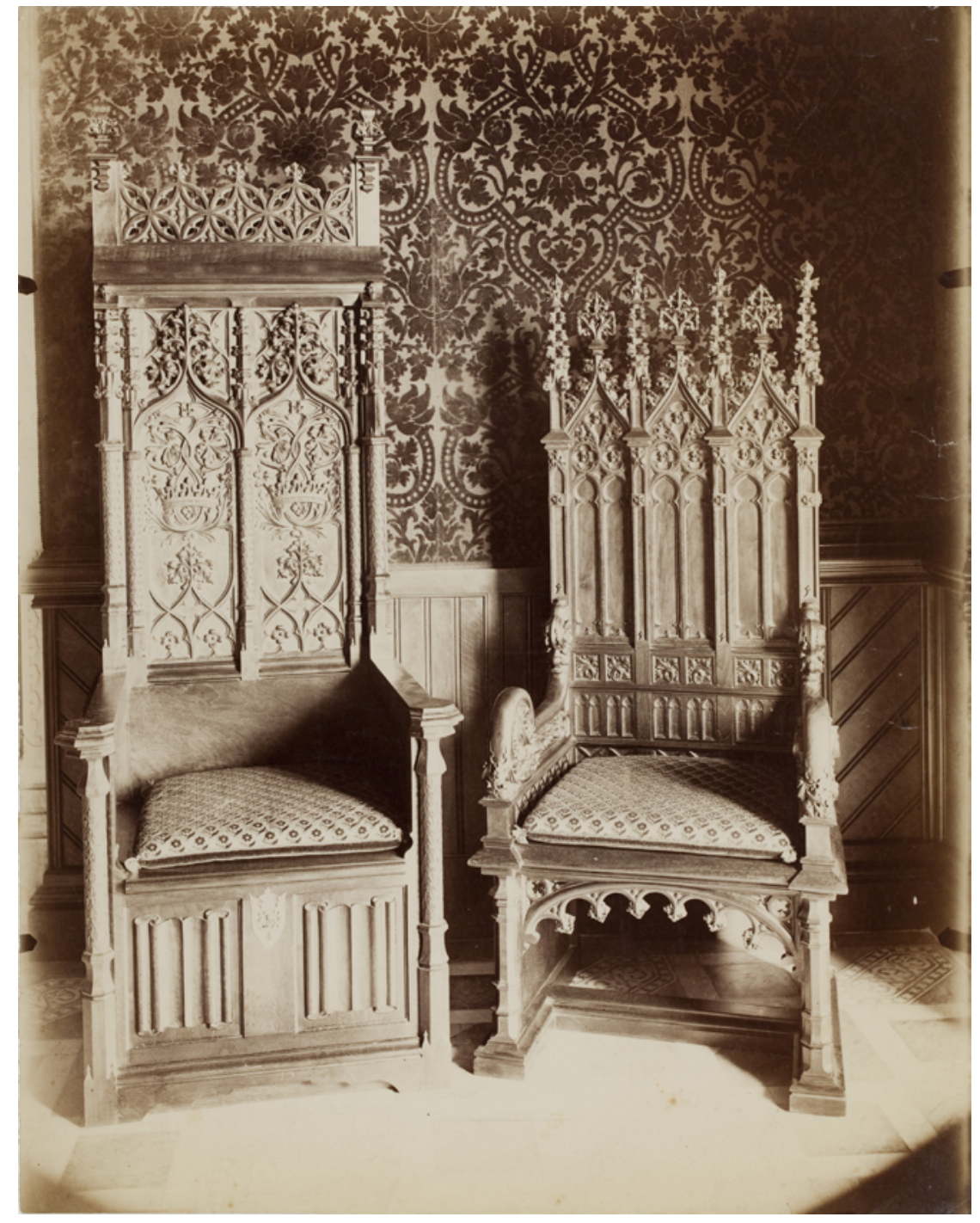

Fig. 4: Pareja de asientos de la sala de estar de la Casa Garí, también conocida como "El Cros". Argentona. Imagen 570877. Arxiu Nacional de Catalunya. 


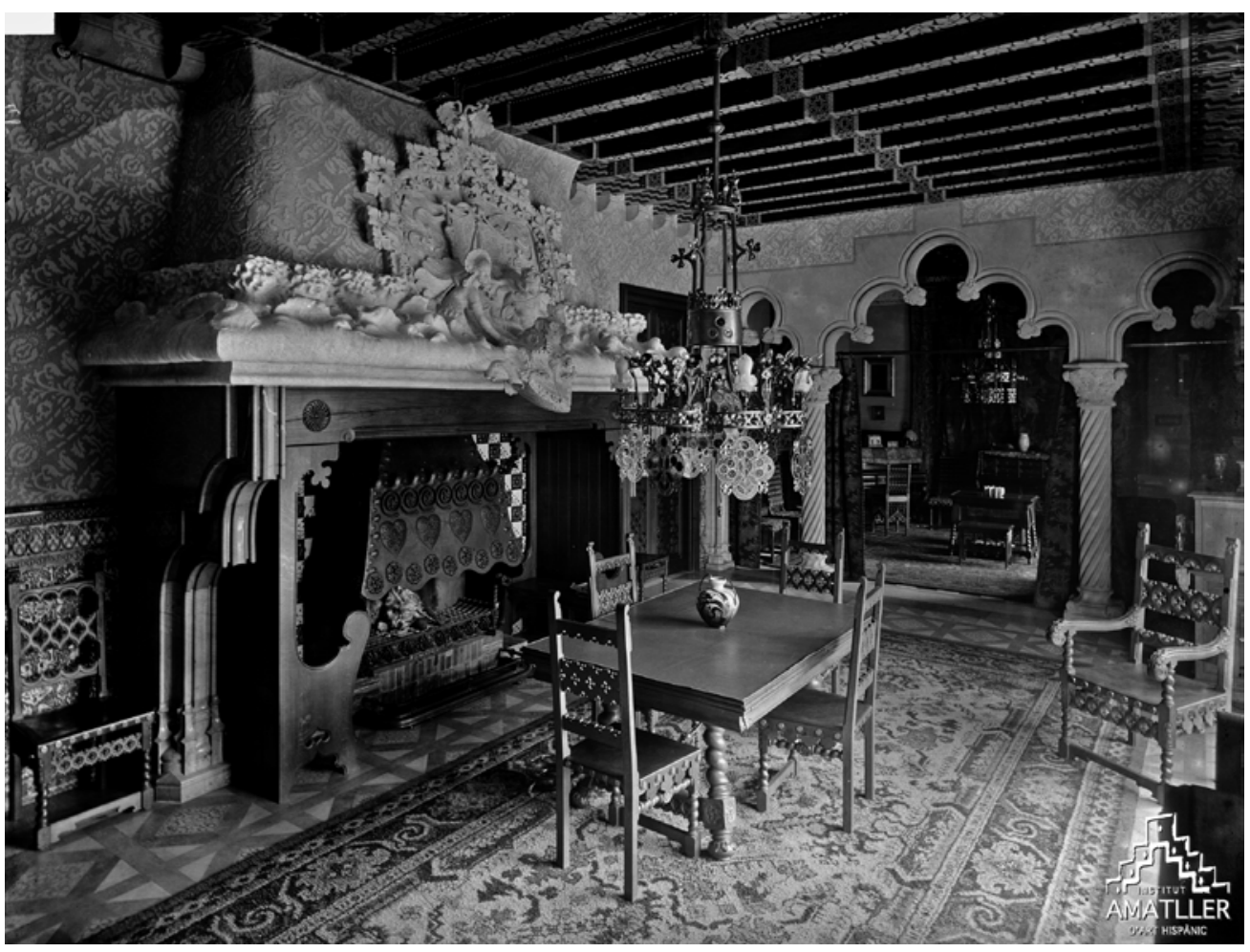

Fig. 5: Comedor y, al fondo, sala de música de la Casa Amatller. Barcelona. 00452015. Fundació Institut Amatller d'Art Hispànic.

De los escaños/arquibancos de respaldo alto que diseñó, se ha podido conservar uno en el salón de la Casa Amatller. Este mueble fue realizado en nogal y con tiradores y bisagras de las tapas del contenedor en latón. ${ }^{35}$ También se aprecia mobiliario de esta tipología en las imágenes del Palau Baró de Quadras. ${ }^{36}$

El aparador fue otro de los muebles incorporados por Puig i Cadafalch a los interiores que diseñó. A diferencia del modelo tinell explicado anteriormente, esta otra tipología de aparador consiste "en una sucesión de estantes abiertos, que forman como una escalera que se adosa a la pared por donde sube un plafón coronado con un pequeño dosel". ${ }^{37}$ Este mueble, equivalente al dressoir francés, sería también dibujado por Viollet-le-Duc en sus interiores ${ }^{38}$ y en la definición de este tipo de pieza en su Dictionnaire. ${ }^{39}$

\section{$\underline{\text { Renacimiento }}$}

Pese a no haberse conservado ninguna cama que siguiera los modelos renacentistas, sí que entre los esbozos de Puig, hay un cabecero, con hiladas de torneados a tres niveles (ANC1-737-T-48).

La tipología de mueble renacentista que trabajaría el arquitecto en más de una de "sus" casas sería la arquimesa. A diferencia de la arquilla, las arquimesas tienen "una tapa o puerta abatible que permitía cerrar de un golpe todos los cajones y compartimentos del interior". ${ }^{40}$

En el Museu del Modernisme, se conserva una que estaba en la Casa Trinxet que seguía los modelos de finales del siglo XVI y principios del siglo XVII. Además, en esta pieza se puede apreciar la influencia del movimiento 
Arts \& Crafts, ya que todas sus piezas (las bisagras, los cerrojos) son funcionales y bellas a la vez. Realizada en citrón de Ceilán y con marquetería de diversas maderas, está colocada sobre un pie de puente con cinco arcos de columnas torneadas, decorado con elementos vegetales en bronce. Algunas de estas arquimesas estaban decoradas con detalles medievales y con arcos ojivales en el pie de puente, como la que se esbozó para la Casa Amatller (ANC1-737-N-10) muy parecida a la conservada en la Casa Garí.

Puig i Cadafalch también diseñó arquimesas con decoraciones plenamente modernistas. Por ejemplo, para la salita de costura de Teresa Amatller, el ebanista Gaspar Homar, realizaría una de tapa no abatible, con una vidriera en la parte central con flores inspiradas en la del árbol del almendro ${ }^{41}$, siguiendo el esbozo del arquitecto. Para el Palau Baró de Quadras, en cambio, Puig i Cadafalch diseñó una que a nivel formal seguía el modelo renacentista pero cuyas decoraciones se enmarcan en el más moderno estilo Art Nouveau, con figuras femeninas danzando alrededor de lo que parece un naranjo (ANC1737-N-19). (fig.6)

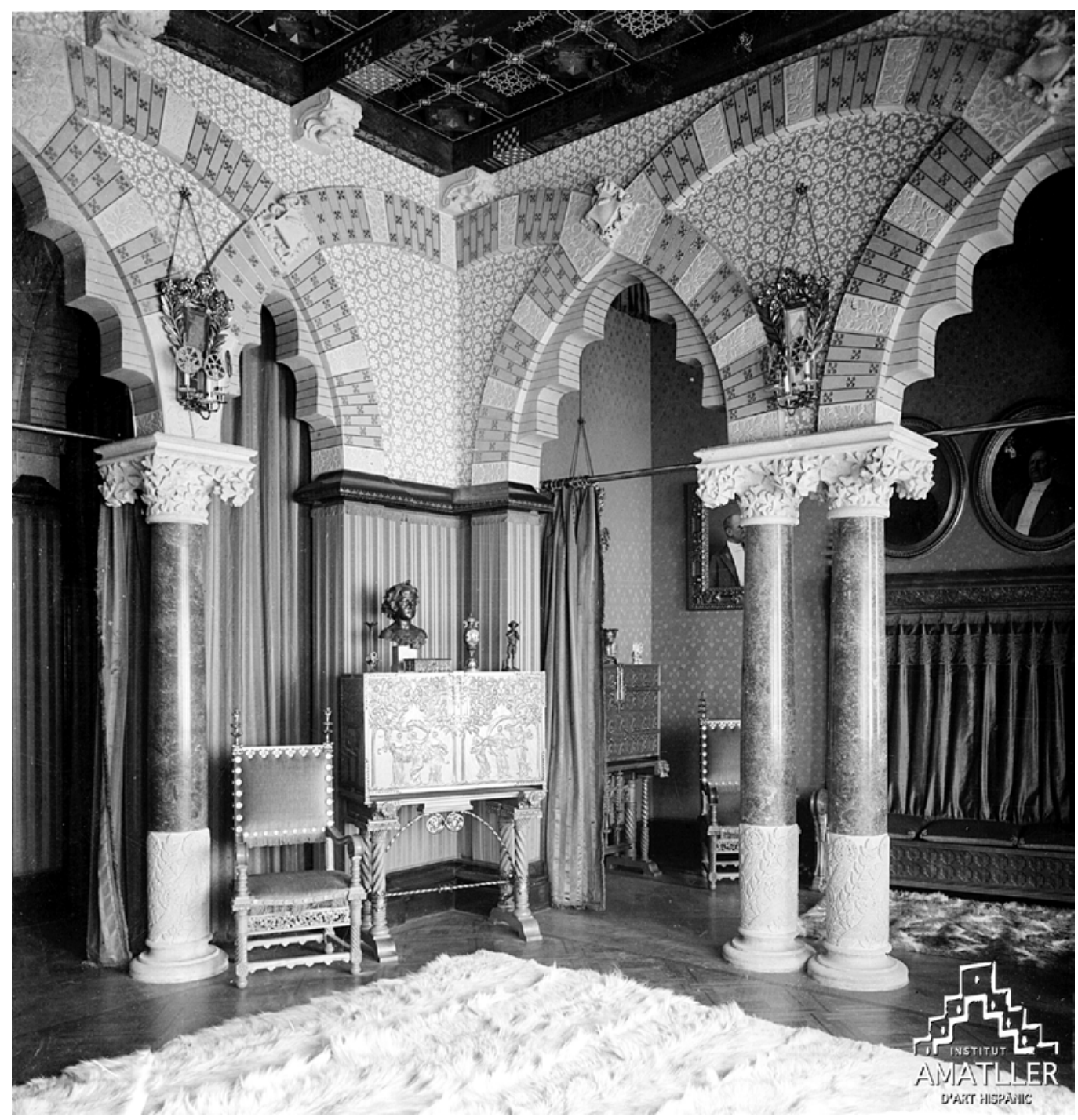

Fig. 6: Salón del Palau Baró de Quadras. Barcelona. 00427006.

Fundació Institut Amatller d'Art Hispànic. 


\section{$\underline{\text { Barroco }}$}

Puig esbozó sillas de estilo barroco (ANC1-737-N-250 250.121a), que se realizaron tanto para la Casa Garí como para el Palau Baró de Quadras. Estas sillas tan habituales en el siglo XVIII tenían el asiento de enea, el respaldo en escalera y podían tener detalles tallados en el florón y en otras partes de la si$\mathrm{lla}^{42}$. En el caso de las diseñadas por Puig y Cadafalch, estos elementos en talla tenían forma de tréboles, motivo vegetal muy habitual en la obra del arquitecto, presente en muebles, suelos o esgrafiados. (fig.7)

En otro de los esbozos (ANC1-737-T-48) se aprecian las formas de una cornucopia, habitual en las casas del siglo XVIII para reflejar la luz de las velas y dar mayor luminosidad a las estancias.

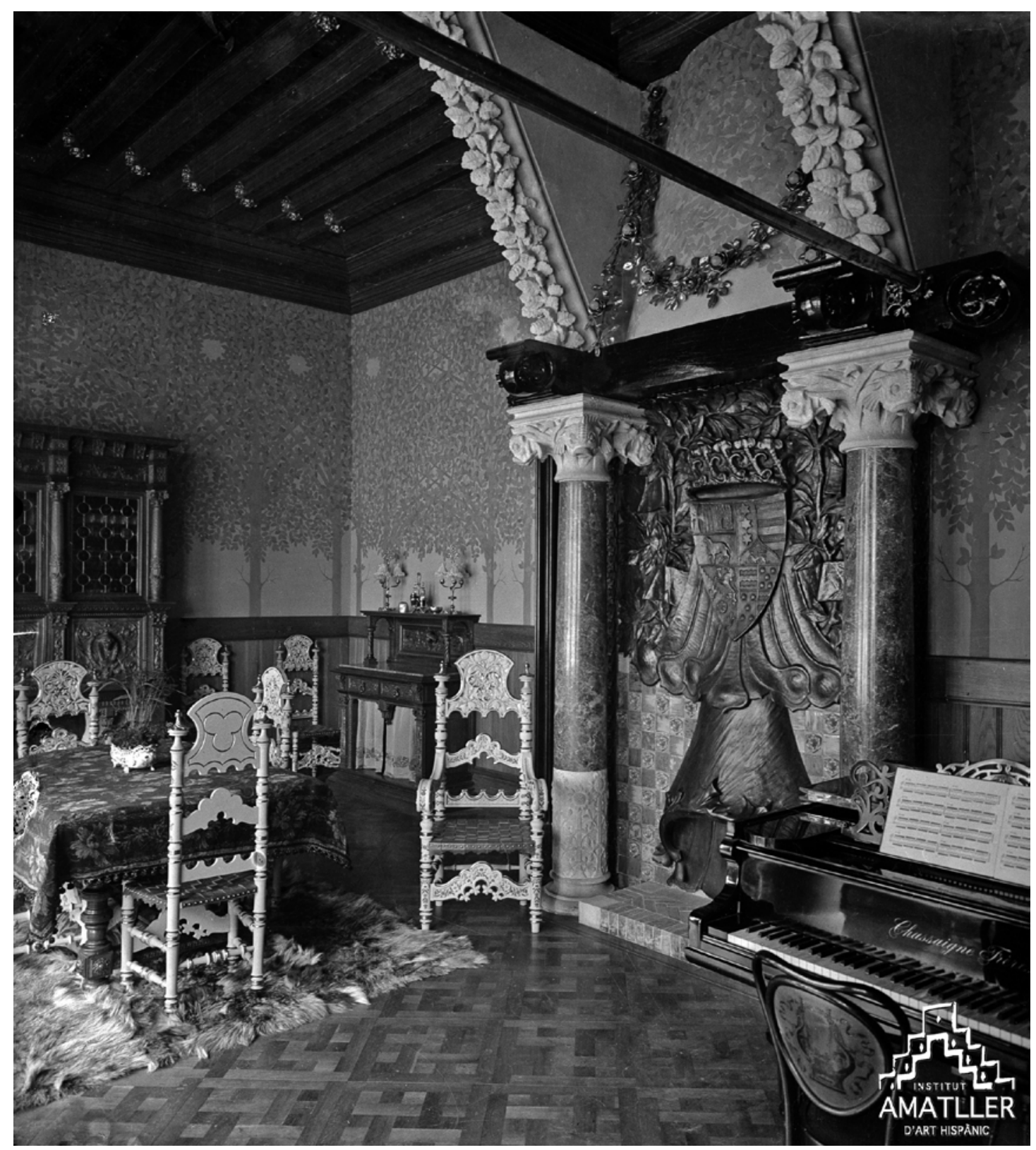

Fig. 7: Comedor y piano del Palau Baró de Quadras. Barcelona. 03765002. Fundació Institut Amatller d'Art Hispànic 


\section{Estilo imperio}

De esta estética, adaptada en España como estilo fernandino, hay el esbozo (ANC1-737-T-48) del cabecero de una cama, en forma de copa con dos esfinges aladas en la parte inferior. Para algunos autores ${ }^{43}$, este tipo de trabajos "dieron a las alcobas del siglo XIX un aire imponente y lujoso".

\section{Historicismos}

En uno de los esbozos de Puig i Cadafalch (ANC1-737-N-7 7.112a) se puede ver una silla parecida al modelo Phoebus que fue trabajado tanto por los talleres Vidal como Busquets en la segunda mitad del siglo XIX ${ }^{44}$ en Barcelona. Ésta se inspiraba en la tipología tradicional de sillas del Tirol y se ha conservado una de ellas (realizada por Joan Busquets) en el Museu del Modernisme. ${ }^{45}$

\section{$\underline{\text { Modernismo }}$}

También el modernismo más parecido al Art Nouveau fue una referencia para Puig i Cadafalch. No sólo en elementos decorativos de tipologías de mueble más antiguas (como se ha comentado sobre las arquimesas) sino también en piezas como las sillas diseñadas para la salita de costura de Teresa Amatller. Éstas, en madera de fresno, destacan por su decoración floral (personalizada en algunos casos: árboles del almendro ${ }^{46}$ ) y su ligereza. (fig.8)

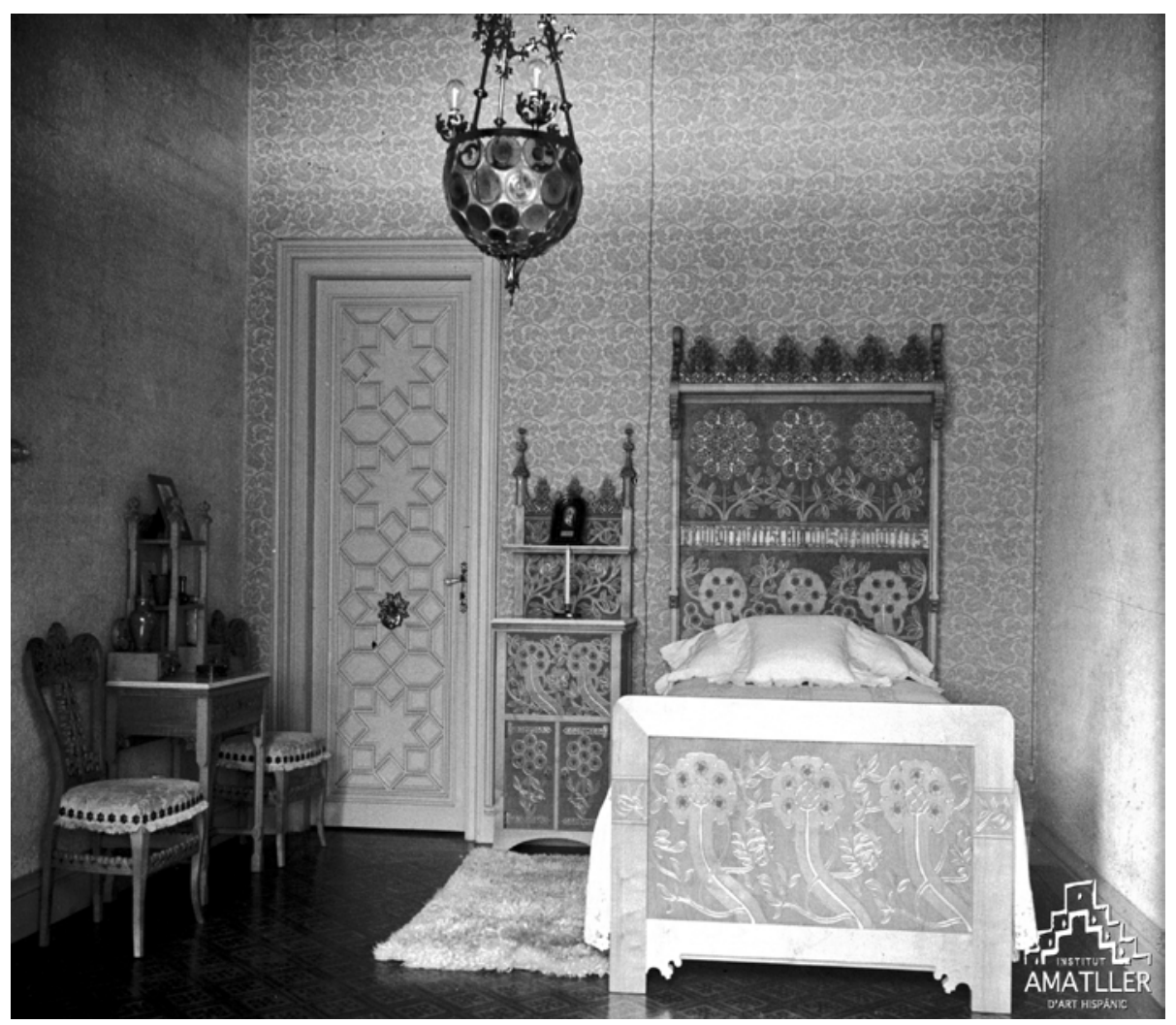

Fig. 8: Dormitorio de Teresa Amatller en Casa Amatller. Barcelona. 01473008. Fundació Institut Amatller d'Art Hispànic 


\section{Conclusiones}

Puig i Cadafalch hizo gala de sus conocimientos como historiador del arte y como arquitecto seguidor de las corrientes europeas. A la hora de diseñar, buscó referencias en el pasado pero les supo dar un toque contemporáneo, como muestran la arquimesa del Palau Baró de Quadras comentada o los escaños de la Casa Amatller, cuyas decoraciones curvilíneas no son propias ni del renacimiento ni del medievo, respectivamente.

El estudio de sus esbozos permite conocer qué estilos artísticos le sirvieron de inspiración. Dado que hasta el momento el neogótico había triunfado en muchos interiores, teniendo en cuenta las ideas de Puig i Cadafalch herederas de la Renaixença y con los ideales de Morris (probablemente) presentes, se entiende que el gótico fuera el estilo donde el arquitecto buscara más a menudo sus modelos. Él mismo escribiría: ${ }^{47}$

Totes les meves obres han nascut de la mateixa font: un intent de renovar l'art gòtic. No un gòtic de fira amb què aixeca temples la devoció francesa, no un gòtic d'arquitectes del temps de Lluís XV, gòtic de guix o de cartró pedra, no un gòtic a la Viollet-le-Duc, sec com una restauració arqueològica de qui no sent l'esperit de l'època, sinó amb la pretensió de fer reviure son esperit, impregnat de l'art del nostre temps, amb la independència i la llibertat d'una obra nova.

Pero no fue el único. El renacimiento, el barroco, el estilo imperio... incluso la obra de ebanistas y mueblistas contemporáneos le sirvieron de muestra. Pese a que en ocasiones, como se ha visto, algunos de sus diseños no eran genuinos sino que los copiaba de la obra de Viollet-le-Duc por ejemplo, o del volumen octavo de la Historia General del Arte, hay otros que salieron de su mano. Conocer más a fondo la bibliografía que pudo consultar Puig i Cadafalch, permitiría conocer más libros de los que pudo copiar o tomar referencias sus piezas de mobiliario.

$\mathrm{Al}$ concebir los interiores como un todo, diseñó todos sus elementos, más allá del ámbito simplemente arquitectónico. No es una característica que solamente trabajara él en aquella época. Como explica Pilar Vélez:

La euforia arquitectónica permanecía ligada a otro hecho decisivo: el papel del arquitecto como coordinador de una obra, donde las artes industriales son el sustrato básico. Porque el interés del arquitecto, ya totalmente profesionalizado, no radica solamente en el armazón arquitectónico, sino que se ocupa también de su interior, de su acabado y de su confort. De aquí se entiende que controle y llegue a diseñar los pavimentos, el hierro forjado de rejas y balcones, las vidrieras, el mobiliario o las piezas cerámicas de la decoración tanto interior como exterior del edificio". ${ }^{48}$

Gaudí, por ejemplo, fue también diseñador de mobiliario, pero en el caso de Puig i Cadafalch, al haberse conservado sus esbozos, se puede trazar un 
camino que permite ir desde su fuente de inspiración hasta, en muchos casos, el mueble final. Pese a ser su faceta más desconocida, sus trabajos como diseñador de interiores pueden compararse a su obra arquitectónica.

Afortunadamente, el hecho de que se hayan conservado in situ los muebles de la Casa Garí o de la Casa Amatller permite hacer un viaje en el tiempo, a la vez que ayuda a entender mejor cuál era su idea de cómo debía ser un hogar. También, se puede disfrutar de sus interiores y conocerlos hojeando aquéllos que él mismo hizo fotografiar para su libro L'oeuvre de Puig $i$ Cadafalch architecte 1896-1904 o con las imágenes que se conservan en el Arxiu Nacional de Catalunya y en la Fundació Institut Amatller de l'Art Hispànic.

\section{NOTAS}

${ }^{1}$ Mario Amaya, Art Nouveau (New York: Studio Vista Limited, 1968 [1a ed.1966]), 15.

2 "Noucentisme", Enciclopèdia Catalana. Consultada el 15 de diciembre de 2020, https://www. enciclopedia.cat/ec-gem-2483.xml.

3 "Puig i Cadafalch. Arquitecte de Catalunya", Museu d'Història de Catalunya. Consultada el 17 de diciembre, https://www.mhcat.cat/exposicions/exposicions realitzades/puig i cadafalch. ${ }^{4}$ Tate Cabré, Ruta Puig i Cadafalch (Barcelona: Institut del Paisatge Urbà i de la Qualitat de Vida, ed.2017).

${ }^{5}$ Josep Puig i Cadafalch, L'oeuvre de Puig i Cadafalch architecte 1896-1904 (Barcelona: M. Parera Editor, 1904), 7-8. https://archive.org/details/loeuvredepuigcad00puig/mode/2up

${ }^{6}$ Ramon Planes, "La salvaguarda de l'arxiu de Josep Puig i Cadafalch (Barcelona, juliol-octubre 2006)," Arxius. Butlletí de la Subdirecció General d'Arxius no.48 (tardor-hivern, 2006): 4. http:// continguts.cultura.gencat.cat/arxius/butlleti/hemeroteca/docs/arxius48.pdf

${ }^{7}$ Puig i Cadafalch escribiría en sus memorias "Sempre la realitat és inferior a la il lusió de les coses, com l'obra feta és inferior al projecte i el projecte al croquis" (pág.357). Esta idea, que el arquitecto escribió en referencia al ámbito político, permite visualizar la importancia que daba a los esbozos. ${ }^{8}$ Carla Busquets, Adela Martínez y Rosalba Poveda. "Puig i Cadafalch: restaurar dibuixos i restaurar idees," Butlletí de l'Arxiu Nacional de Catalunya no.43 (febrero, 2016): 9. https://anc. gencat.cat/web/.content/anc/Butlleti ANC/Butlletins/ANC43.pdf

${ }^{9}$ Busquets, Martínez y Poveda. "Puig i Cadafalch: restaurar dibuixos i restaurar idees," 9-10.

${ }^{10}$ Busquets, Martínez y Poveda. "Puig i Cadafalch: restaurar dibuixos i restaurar idees," 10.

${ }^{11}$ Laura Pastor i Isabel Vallès, Cases singulars, personatges singulars (Barcelona: Albertí Editor, 2015), 131.

${ }^{12}$ William Morris, Arts \& Crafts (San Lorenzo de El Escorial: Langre, 2011 [textos de Morris: 1881-1893]), 110.

${ }^{13}$ Judith Rohrer, La nova escola catalana. Arquitectura i política a l'època del Modernisme, 1886-1906 (Barcelona: L'avenç, 2017), 114.

${ }^{14}$ Rohrer, La nova escola catalana. Arquitectura i politica a l'època del Modernisme, 1886-1906, 115 .

${ }^{15}$ Albert Mestres y Mónica Piera, El mueble en Cataluña. El espacio domestico del gótico al modernismo (Manresa: Fundació Caixa Manresa y Barcelona: Angle Editorial, 1999), 68.

${ }^{16}$ Lluís Permanye, Puig i Cadafalch (Barcelona: Ediciones Polígrafa, 2001), 29.

${ }^{17}$ Joaquim Graupera, "La Sala i el Tinell. L'ennobliment decoratiu de les masies post-remences al Baix Maresme (s.XV-XVI)," In marítima no.2 (2019): 153. https://www.raco.cat/index.php/ inmaritima/article/download/381645/474773 
18 “Tinell”, Enciclopèdia Catalana. Consultada el 27 de marzo de 2021, https://www.enciclopedia.cat/ec-gdlc-e00133942.xml

${ }^{19}$ Mestres y Piera, El mueble en Cataluña. El espacio domestico del gótico al modernismo, 71. ${ }^{20}$ VVAA, Extraordinàries! Col leccions d'arts decoratives $i$ arts d'autor (segles III-XX) (Barcelona: Ajuntament de Barcelona, Institut de Cultura i Museu del Disseny de Barcelona, 2014), 218. Cuando fue incorporado, en 1979, a la colección del Museu d'Art de Catalunya se le hizo una importante intervención en la cual se le añadieron y completaron diversas partes.

${ }^{21}$ Santiago Alcolea, Puig i Cadafalch (Barcelona: Lunwerg Editores, 2006), 24.

${ }^{22}$ Eugène-Emmanuel Viollet-le-Duc, Dictionnaire raisonné du mobilier français de l'époque carlovingienne à la Renaissance. Tome premier (Paris: Librairie Centrale d'Architecture), 129. ${ }^{23}$ Francesc Miquel, Historia General del Arte, vol.VIII: Historia del mueble. Tejido, bordado y tapiz (Barcelona: Editorial Montaner y Simón, 1897), 74. https://ddd.uab.cat/record/56958

${ }^{24}$ Josep Mainar, El moble català (Barcelona: Edicions Destino, 1976), 37.

${ }^{25}$ Como esta pieza está esbozada junto a otros muebles que iban destinados a la Casa Amatller y dado que su elaboración es parecida a la del mobiliario allí conservado, es probable que este sitial lo realizará el mismo taller que realizó los demás, el Salat Hermanos.

${ }^{26}$ Mainar. El moble català, 52 y 56.

${ }^{27}$ Mainar. El moble català, 56.

${ }^{28}$ Miquel, Historia General del Arte, vol.VIII: Historia del mueble. Tejido, bordado y tapiz, 75. 29 "Jocs Florals de Barcelona". Enciclopèdia Catalana. Consultada el 8 de enero de 2021. https:// www.enciclopedia.cat/ec-gec-0034693.xml

${ }^{30}$ Mestres y Piera, El mueble en Cataluña. El espacio domestico del gótico al modernismo, 43.

${ }^{31}$ VVAA, Arts decoratives a Barcelona. Col leccions per un museu. Catálogo exposición Museu d'Arts Decoratives, Barcelona, 1994 (Barcelona: Regidoria d'edicions i Publicacions de l'Ajuntament de Barcelona, 1994), 74.

${ }^{32}$ Los dos escaños que pueden verse actualmente a ambos lados de la chimenea son reproducciones hechas a partir de fotografías de la época. La restauración de la Casa Amatller se realizó entre 2009 y 2015.

${ }^{33}$ Viollet-le-Duc. Dictionnaire raisonné du mobilier français de l'époque carlovingienne à la Renaissance. Tome premie, XIII.

${ }^{34}$ VVAA, Museu del modernisme català (Barcelona: Fotoletra, SA, 2010), 93 y 95.

${ }^{35}$ Gracias a que en el ANC se conserva la factura (ANC1-737-T-133) del taller Salat Hermanos que realizó este mueble, se sabe que se pagaron 240 duros por él en el año 1900.

${ }^{36}$ Fundació Institut Amatller de l'Art Hispànic. Arxiu Mas E-23 / 00427006.

${ }^{37}$ Mestres y Piera, El mueble en Cataluña. El espacio domestico del gótico al modernismo, 39.

${ }^{38}$ Viollet-le-Duc. Dictionnaire raisonné du mobilier français de l'époque carlovingienne à la Renaissance. Tome premie, XIV.

${ }^{39}$ Viollet-le-Duc. Dictionnaire raisonné du mobilier français de l'époque carlovingienne à la Renaissance. Tome premie, 102.

${ }^{40}$ Mestres y Piera, El mueble en Cataluña. El espacio domestico del gótico al modernismo, 71.

${ }^{41} \mathrm{El}$ apellido de la familia Amatller, en catalán, significa "almendro", de ahí la elección de este árbol para inspirar las decoraciones de la Casa.

${ }^{42}$ Mestres y Piera, El mueble en Cataluña. El espacio domestico del gótico al modernismo, 130; y Mainar, El moble català 131.

${ }^{43}$ Mestres y Piera, El mueble en Cataluña. El espacio domestico del gótico al modernismo, 228.

${ }^{44}$ Mainar, El moble català 283.

${ }^{45}$ VVAA, Museu del modernisme català, 108.

${ }^{46}$ Ver nota 37. 
${ }^{47}$ Josep Puig i Cadafalch, Memòries (Barcelona: Publicacions de l'Abadia de Montserrat, 2003), 70

${ }^{48}$ Albert García (dir.), El Modernismo (Barcelona: Editorial Olimpíada Cultural SA y Lunwerg Editores SA, 1990), 235. 